\title{
semeando métodos
}

\section{Natalia de Avila Gavaleante Maria Celeste Almeida Wanner Raoni Garvalho Gondim}

\section{Introdução}

\section{Mato Grosso-BA, primavera de 2014.}

Estávamos em pesquisa de campo na Chapada Diamantina, abertos a experiências que nos trouxessem conteúdo para a construção do livro-obra Pó.Boi.Pedra - Percografiasi', até então, sem nome. Subíamos a montanha saindo de Rio de Contas, no intuito de encontrar o cultivo de flores que eventualmente víamos nas janelas e salas das casas de fachadas tombadas. A aridez do sertão contrastada com os imensos arranjos coloridos não nos parecia uma imagem muito congruente. De onde vinha tudo aquilo? Tão florido, fresco e colorido... 
Subíamos a montanha, e a medida que a paisagem se orvalhava, essa bruma nos tomava; algo estava silenciosamente sendo sorvido - a sutileza do espaço, manifestada pela incerteza do tempo - um timespecific.

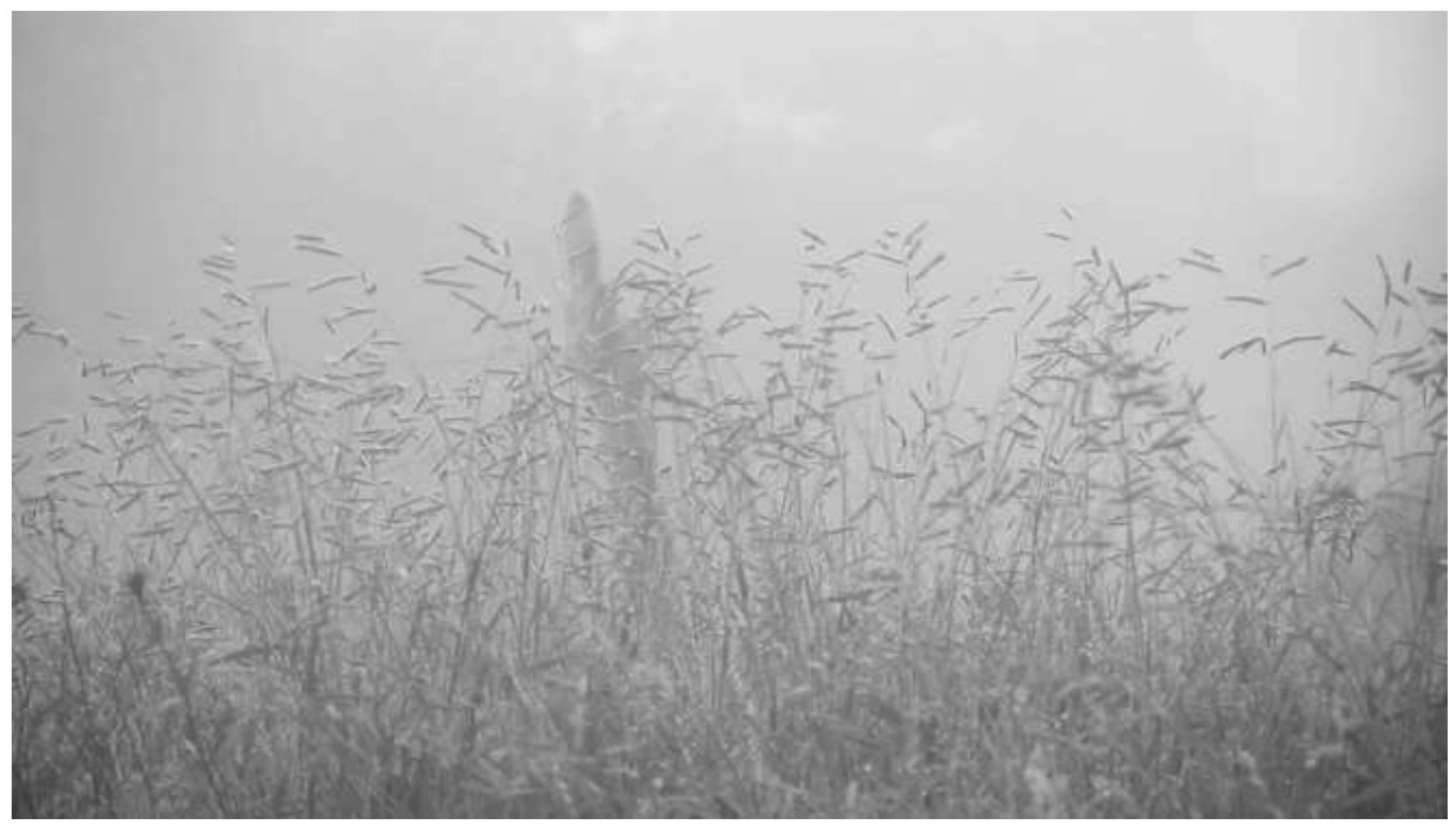

Raoni Gondim. Mato Grosso - Rio de Contas - BA/2014.

O corpo: pequenas ações (reações), armazenamento de sensações (poética) de substâncias contidas no instante. O que é uma experiência? Entre o corpo e o mundo, permeia um estado rarefeito: a linguagem. Enxergar não é preciso. Entre o corpo e o mundo, o devaneio trabalhava as nossas paisagens internas. A constituição do instante (timespecific) perpassa a imagem que se finda na memória: imaginário. Aquela neblina nonada era o que nos fazia perder o senso de fronteira, eram corpos no espaço e espaços corpóreos... Aquelas flores perduravam; sempre-vivas. Quanto a nós, estávamos suspensos; "como pode um pressentimento acontecer de trás pra frente?" (Migracielo, 2014, pg s/n).

Estamos num lugar de onde a experiência se consolida a partir das sensações, e com essas sensações 
o imaginário trabalha a imagem como devaneio, conforme a fenomenologia do imaginário de Gaston Bachelard (1984). Pois, em suma, procuramos no presente artigo, delinear um percurso da construção material, oriundo de sua ontologia, ou seja, das sensações que nos são atribuídas via a experiência. Nesse sentido, recorremos a premissa de que não há imagem sem imaginação, dito que essa se trata de um rastro do real, um traçado heterogêneo, de um conteúdo editado.

Subimos a rua da comunidade, era manhã-cedo. Perguntávamos pelos quintais floridos e seguíamos nos passos descritos pelos vizinhos. Palavra tem corpo? - na convergência de relações entre a imaginação e a memória, pensamos sua constituição; quando uma sensação evanesce na memória a experiência se torna uma recordação - Batemos na porta, uma criança de pijama nos atende;

Bom dia na pequena vila,

Pés descalços na soleira

Lembranças com cheiro de café-torrado.

A imagem é também uma experiência. Ao retomarmos o território fantasmático do imaginário, lugar onde o devaneio trabalha suas paisagens internas, imagem-princeps ${ }^{i i}$ - imagem criadora que contém uma força contundente como uma gravura, como se na memória tivesse sido talhada e não apenas gravada. "São sempre lembranças e lendas ao mesmo tempo", diz (BACHELARD, 1984, p. 2018), imagens atualizadas a partir desse princípio ordenador e criador; corpo é vida acontecendo. E o tempo? A sutileza do espaço (um corpo), manifesta em incertezas (heterogenias).

Pois que a criança fica nos encarando de corpo tímido e sorriso amigo. Ao que nos parece, sua mãe, se ocupara da casa... Na porta, mais dois se aproximam: A mãe e uma barriga que urge. Novos pés descalços na soleira...

No clima medievo, um tempo arrastado. Aquela mãe gestante, era em verdade filha. Com o mesmo corpo tímido, pés na soleira e sorriso amigo, nos explicava que tal como a casa, o quintal era de sua mãe e essa, saíra cedo para vender seus cultivos na comunidade vizinha. Solícita, aquela grande mulher 
nos leva até o pequeno quintal repleto de sempre-vivas, vivas! E com uma pequena faca de mesa, se abaixando em equilíbrio com a grande barriga, colhe carinhosamente, cada ramo com apenas uma mão. Um certo desconforto em colocar a filha gestante para colher as sempre-vivas nos acomete, uma função que não nos parece muito própria para suas tantas semanas de gestação, e, então, em meio às flores, ouve-se "Esse é o trabalho que eu mais gosto de fazer na vida!". Corpo e vida acontecendo.

É justamente porque as imagens não estão no presente que são capazes de tornar visíveis e sensíveis às relações de tempo mais complexas que incumbem a memória na história, pontua Didi-Huberman (2008), pois a memória também é sutileza do espaço manifestada pela incerteza do tempo; numa outra instância, pois nesse caso, a memória como um substrato da experiência é decantada num outro instante - atualização da realidade: experiência - imagem / narrativa - experiência. Ao retomar o espaço da experiência na imagem, procuramos nas frestas dos conteúdos, uma materialidade recorrente capaz de renovar a nossa linguagem e o pensamento.

Essa materialidade outrem, representa uma constante e imanente organização do espaço de criação; lugar onde as coisas são pensadas, sentidas, elaboradas, refletidas, construídas, desconstruídas, mencionadas, editadas, recortadas, relembradas... E tudo isso, são imagens acontecendo.

A experiência como conteúdo primordial e combustível de todo esse processo que se retroalimenta se processa e se encaminha, na experiência. O jogo, a imanência de elaboração de significados que a experiência nos possibilita, a estrutura lúdica, um comportamento restauradoiii; organizado a partir do acesso pelo espaço imaginário para que haja uma simbolização dos acontecimentos e novas imagens.

Esse território de formação da imagem pelo imaginário, está também na ideia de leitura como performance ${ }^{\mathrm{iv}}$ onde, já que o investimento de sentido é uma ação do e no imaginário para a formação de novas imagens, e que este "investimento" seria uma leitura a se dar na duração da experiência, toda leitura seria um ato performático. E se a leitura, enquanto ato performático, é um investimento de sentido, Paul Zumthor (2007) adianta que esse acontecimento é território da linguagem, logo, desde que existe linguagem, existe performance enquanto mecanismo de simbolização oriundo do imaginário. "Para que a mensagem metacomunicativa "isto é brincadeira" possa funcionar, alguma 
operação mental precisa estabelecer o que está e o que não está incluído nesse "isso" "(CARLSON, 2010, p. 28).

A metacomunicação, enquanto estrutura de linguagem, compreende a performance como um ato de organização da experiência, onde a memória trabalha ativamente na leitura/ percepção da ação, ou seja, um acontecimento onde o imaginário trabalha junto à experiência, no intuito de que novas imagens sejam elaboradas, a partir da relação entre a memória, que subjaz no imaginário, e o contexto do instante. Portanto, quando a sensação se transforma em sentido, o texto se torna um campo ampliado e a linguagem, polissêmica. O instante enquanto fugacidade da imagem; território de sensações, lugar onde as experiências são compreendidas na relação afetiva com nosso conteúdo interno.

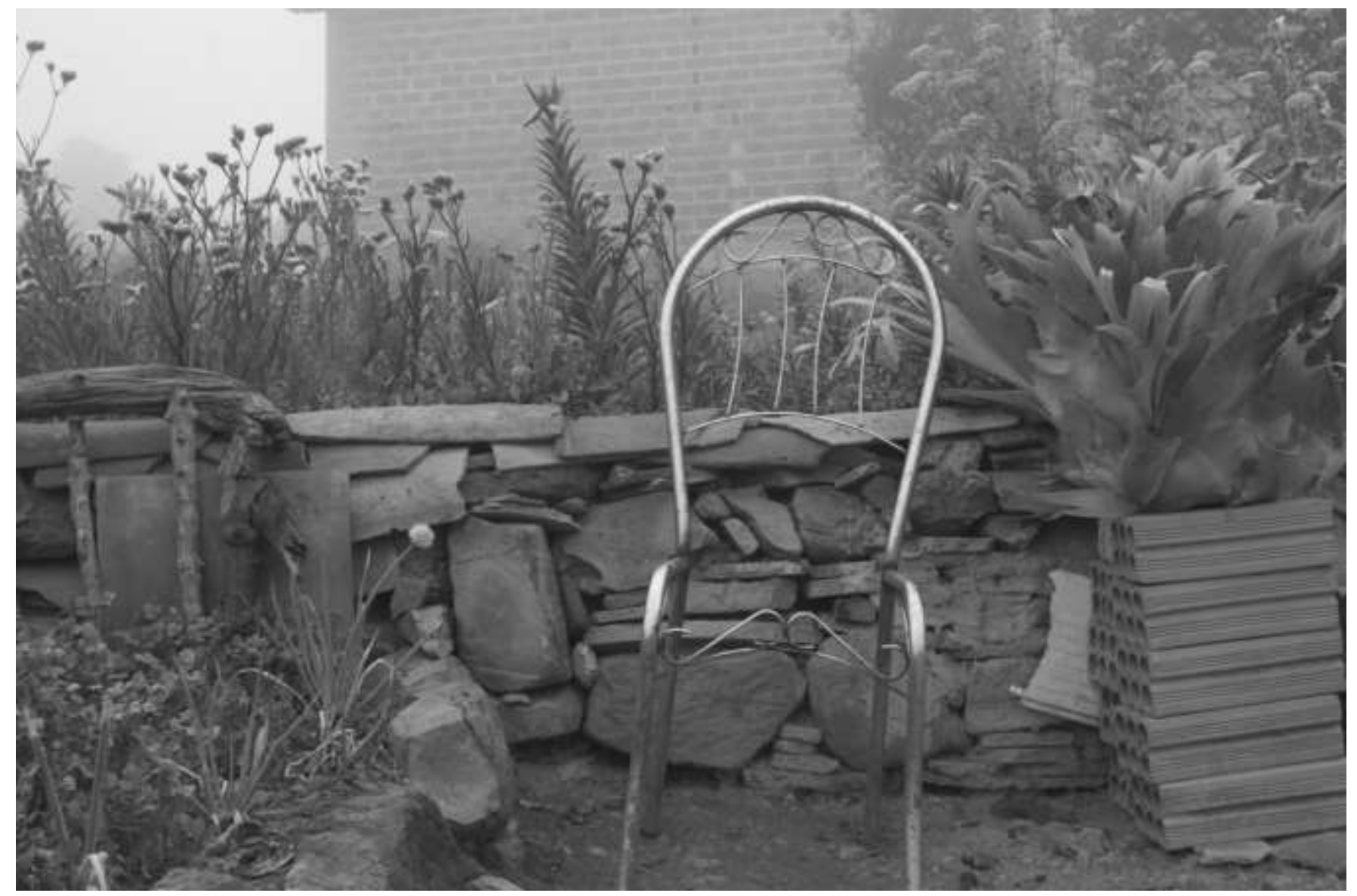

Natalia Cavaleante. Mato Grosso - Rio de Contas - BA/2014 


\section{meta-método}

Se nos territórios caminhantes da experiência, essa materialidade se consolida na imagem a partir da sensação, como traduzi-las se não pela afetividade? O processo investigativo não prevê necessariamente um início, mas pontos de aprofundamento por afeto, onde a essência é relacional. $O$ sujeito da experiência é um território de passagem e esse movimento é proveniente de forças heterogêneas, pois "a lógica da experiência produz diferença, heterogeneidade e pluralidade" (LARROSA, 2014). Por isso tangenciamos pela heterogenia; o espaço das sensações.

A cartografia incitada por Deleuze e Guatarri (2000), que compreende a natureza das nuanças do processo de criação, sobretudo quando os caminhos percorridos, em um espaço corporal, são mesclados a espaços virtuais, de ordem fantasmagórica, incorpórea e sensória; ao caminho, a potência, e a carga simbólica.

Essa potência e vastidão da imagem constroem uma poética e experimenta a linguagem pela polissemia; paisagem. Traz para o jogo da metacomunicação, para a brincadeira de atribuir sentido o espaço da metalinguagem, de apreensão por meio do corpo-território; afetividade. Campo de investigação elementar, visto que é primeiramente pelo corpo que experienciamos e, através da relação afetiva [imaginário], que investimos energia à percepção de novos sentidos. Desse modo, o corpo-território se torna o instrumento primordial de percepção, interação, construção e leitura por sua capacidade de tudo isso mensurar na vastidão das instâncias, a fim de que se promovam novas imagens e novas qualidades de imagens.

Portanto, o que é a experiência, o que é a obra e como estas se relacionam, dito que não são a mesma coisa? A Percografia seria um método, uma metodologia e uma poética que se ocupa em esmiuçar tais possibilidades que se aprofundam por meio da proliferação das ações e relações dessa heterogenia, numa tentativa de identificar, na experiência, pontos de recorrência que se organizam na poética, através de linguagens distintas.

Ao retomar à arte, a partir desse espaço sutil, mais amiúde do que o suporte que a posteriori apresenta 
a coisa em si, o que nos interessa é a coisa não editada, sem borda, entregue à evasão de sentido. Pois sedução é aquilo que nos instiga a uma aproximação do outro; é a possibilidade pelo vazio; disponibilizar-se ao acaso do porvir, como uma atitude de presença: contemplação no existir. Em suma, de uma insurgência forjada pelo atravessamento de um dado que se sobressai ao acaso.

\section{consideraçöes finais}

É no imaginário; território dominante da imaginação (campo de faculdades criativas, produtora de imagens) que reencontramos toda uma experiência vivida em uma imagem, no sentido em que, uma vez que estas experiências evidenciam imagens internas em nosso pensamento, concebemos uma representação codificada do real. Portanto, é através da Percografiav enquanto método, metodologia e poética, que transitamos por tais questões, na qual permitimos que a experiência tutele a poética e os processos criativos que a circundam. No intuito por construir uma narrativa, é que a experiência como um instrumento, nos coloca a caminho; atentos ao espaço que se abre, enquanto possibilidades. Um espaço de enfrentamento que fricciona por meio do imaginário, a linguagem porvir.

\section{REFERÊNMIAS}

BACHELARD, Gaston. A Poética do Espaço. 2 ed. São Paulo: Martins Fontes, 2008. CARLSON, Marvin A. Performance: uma introdução critica. Editora UFMG, 2010

DELEUZE, Gilles; GUATARRI, Félix. Mil platôs: capitalismo e esquizofrenia. Rio de Janeiro:34, 1997a. v. 4 e 5.

\&. Migracielo. Novo Corpo Amoroso. Coleção Civilizações. Outr\&n Editorial. Salvador - Porto Alegre, 2014.

DIDI-HUBERMAN, Georges. Quando as imagens tocam o real. Trad: Patrícia Carmello e Vera Casa Nova. 2008

LARROSA, Jorge Bondía. Notas sobre a Experiência e o saber de experiência. Belo Horizonte, 2002.

WANNER, Celeste; CAVALCANTE, Natalia; ALMEIDA, Tarcísio; GONDIM, Raoni. Pó. Boi. Pedra - Percografias. Cian, Bahia 2015 .

SCHECHNER, Richard. O que é performance? O percevejo, Rio de Janeiro, ano 11, n. 12, p. 25- 50, $2003 a$.

ZUMTHOR, Paul. Performance, recepção, leitura. São Paulo: Cosac \& Naify, 2007 
i o Livro-Obra Pó.Boi.Pedra - Percografias é resultado de uma pesquisa pratico-teórica, organizado pelos pesquisadores Celeste Wanner, Natalia Cavalcante, Raoni Gondim e Tarcísio Almeida, produzido via Edital PROEXT/ARTES - 2014, cujo conteúdo apresentado compreende uma narrativa visual, a partir de experiências transdisciplinares, dos organizadores e colaboradores que direta e indiretamente corroboram na insurgência dessa narrativa heterogênea.

ii Bachelard, 1984

iii Richard Schecher, 2006.

iv Paul Zumthor, 2007

$\checkmark$ Palavra criada por Raoni Gondim 